in vivo $34: 2727-2731(2020)$

doi:10.21873/invivo.12094

\title{
Pre-Treatment Seizures in Patients With 1-3 Cerebral Metastases Receiving Local Therapies Plus Whole-brain Radiotherapy
}

\author{
JASPAR WITTELER ${ }^{1}$, TROELS W. KJAER ${ }^{2}$, SOEREN TVILSTED $^{3}$, STEVEN E. SCHILD $^{4}$ and DIRK RADES ${ }^{1}$ \\ ${ }^{1}$ Department of Radiation Oncology, University of Lübeck, Lübeck, Germany; \\ ${ }^{2}$ Neurological Department, Zealand University Hospital, Roskilde, Denmark; \\ ${ }^{3}$ Research Projects and Clinical Optimization, Zealand University Hospital, Koege, Denmark; \\ ${ }^{4}$ Department of Radiation Oncology, Mayo Clinic, Scottsdale, AZ, U.S.A.
}

\begin{abstract}
Background/Aim: Seizures impair patients' quality of life. The prognostic role of pre-treatment seizures in patients with 1-3 cerebral metastases receiving local therapies plus whole-brain radiotherapy (WBRT) was investigated. Patients and Methods: In 249 patients, prevalence, risk factors and associations of pre-treatment seizures with survival were retrospectively evaluated. Age, gender, performance score, tumor type, number of lesions, extra-cerebral metastases, and time from tumor diagnosis to treatment of cerebral metastasis were analyzed for associations with seizures. These characteristics and pretreatment seizures were also analyzed for associations with survival. Results: The prevalence of pre-treatment seizures was $24.1 \%$. Trends for associations were found between seizures and gender or performance score. On multivariate analysis, age $(p=0.008)$, performance score $(p=0.004)$, tumor type $(p<0.001)$ and extra-cerebral metastasis $(p<0.001)$ were significantly associated with survival. Conclusion: Seizures were comparably common prior to local therapies plus WBRT for cerebral metastases. No factor was found to be significantly associated with seizures, and seizures were not associated with survival.
\end{abstract}

Seizures are a serious problem in patients with both primary and secondary brain tumors (1). For the latter group, different

This article is freely accessible online.

Correspondence to: Prof. Dirk Rades, MD, Department of Radiation Oncology, University of Lübeck, Lübeck, Ratzeburger Allee 160, 23562 Lübeck, Germany. Tel: +49 45150045401, Fax: +49 45150045404, e-mail: dirk.rades@uksh.de

Key Words: Seizures, cerebral metastasis, local therapies, prevalence, risk factors, survival. treatment protocols are administered, depending mainly on the type of primary tumor and the number of cerebral lesions (2). The vast majority of patients with multiple cerebral metastases, often defined as four or more lesions, receive whole-brain radiotherapy (WBRT) alone $(2,3)$. In patients with oligo-metastatic disease (less than four lesions), local therapies such as neurosurgery, stereotactic radiosurgery (SRS) or other radiation boost techniques are frequently used $(2,4)$. In a considerable number of patients with oligometastatic cerebral disease, particularly in those patients with a high risk of developing new cerebral metastases outside the treated areas, local therapies are combined with WBRT (5-7). In contrast, patients with a limited number of cerebral metastases from less radiosensitive tumors such as malignant melanoma are often treated with neurosurgery or SRS alone (2). Since the risk of pre-treatment seizures is also associated with the number of cerebral metastases and primary tumor type, the prevalence of seizures varies between the groups receiving different treatments, namely WBRT alone, neurosurgery or SRS alone and local therapy plus WBRT (8, 9). Therefore, it appears reasonable to perform separate studies for these groups. The present study focused on patients treated with local therapy plus WBRT for 1-3 cerebral metastases and investigated the role of pre-treatment seizures, in terms of prevalence and potential risk factors, as well as their association with survival.

\section{Patients and Methods}

In a cohort of 249 patients with 1-3 cerebral metastases, who received a local therapy plus WBRT between 1997 and 2019, the role of pre-treatment seizures (prevalence, risk factors and association with survival) was retrospectively evaluated. Local therapies included neurosurgical resection $(n=163)$, stereotactic radiosurgery or fractionated stereotactic radiotherapy $(n=70)$ and a simultaneous integrated boost $(n=16)$. The study received approval from the local ethics committee (University of Lübeck, 20-120A). 
Table I. Distribution of patient characteristics.

\begin{tabular}{llc}
\hline Characteristic & & $\begin{array}{c}\text { Number of } \\
\text { patients }(\%)\end{array}$ \\
\hline Pre-treatment symptoms & No symptoms & $5(2)$ \\
& Seizures alone & $33(13)$ \\
& Seizures+other symptoms & $27(11)$ \\
& Other symptoms alone & $184(74)$ \\
Pre-treatment seizures & Seizures & $60(24)$ \\
& No seizures & $189(76)$ \\
Age & $\leq 60$ Years & $122(49)$ \\
& $\geq 61$ Years & $127(51)$ \\
Gender & Female & $134(54)$ \\
& Male & $115(46)$ \\
Karnofsky PS & $\leq 70 \%$ & $91(37)$ \\
& $\geq 80 \%$ & $158(63)$ \\
Primary tumor type & Breast cancer & $55(22)$ \\
& NSCLC & $104(42)$ \\
& SCLC & $29(12)$ \\
& CUP & $20(8)$ \\
Number of cerebral lesions & Other tumor types & $41(16)$ \\
& 1 & $174(70)$ \\
Extra-cerebral metastasis & 2 or 3 & $75(30)$ \\
Time from tumor diagnosis & Yes & $104(42)$ \\
to treatment of cerebral & No Months & $145(58)$ \\
metastasis & $\geq 10$ Months & $128(51)$ \\
& & $121(49)$ \\
& & \\
& &
\end{tabular}

PS: Performance score; NSCLC: non-small cell lung cancer; SCLC: small-cell lung cancer; CUP: cancer of unknown primary.

The following characteristics were analyzed for associations with pre-treatment seizures: Age ( $\leq 60 v s . \geq 61$ years, median=61 years), gender, Karnofsky performance score $(\leq 70 \% v s . \geq 80 \%$, median $=80 \%)$, primary tumor type [breast cancer $v s$. non-small cell lung cancer (NSCLC), small cell lung cancer (SCLC), cancer of unknown primary (CUP) and other $(n<20)$ tumor types], number of cerebral lesions $(1 v s$. 2 or 3), extra-cerebral metastasis (yes $v s$. no) and time from tumor diagnosis to treatment of cerebral metastasis ( $\leq 9 v s . \geq 10$ months, median $=10$ months). In addition, these characteristics were analyzed for survival as were pre-treatment symptoms (no symptoms $v s$. seizures alone, seizures+other symptoms and other symptoms alone) and pretreatment seizures [yes (seizures \pm other symptoms) vs. no] (Table I).

For the analyses of potential associations with seizures the Chisquare test was used and $p$-values of $<0.05$ indicated a significant association. Survival times were calculated from the first day of treatment for cerebral metastasis. Survival analyses were performed using the Kaplan-Meier method plus the log-rank test. Again, $p$ values of $<0.05$ were considered significant, and the corresponding characteristics were included in a multivariate Cox regression analysis. If a $p$-value was $<0.05$, the characteristic was considered an independent predictor of survival.

\section{Results}

In the present series, prevalence of pre-treatment seizures was $24.1 \%$ (60 of 249 patients). Seizures alone occurred in
Table II. Associations between patient characteristics and pre-treatment seizures.

\begin{tabular}{lcc}
\hline Characteristic & $\begin{array}{c}\text { Number of patients } \\
\text { with seizures }(\%)\end{array}$ & $p$-Value \\
\hline Age & & \\
$\quad \leq 60$ Years & $31(25.4)$ & 0.68 \\
$\quad \geq 61$ Years & $29(22.8)$ & \\
Gender & & 0.059 \\
$\quad$ Female & $25(18.7)$ & \\
$\quad$ Male & $35(30.4)$ & \\
Karnofsky performance score & $16(17.6)$ & 0.11 \\
$\quad \leq 70 \%$ & $44(27.8)$ & \\
$\quad \geq 80 \%$ & $17(30.9)$ & 0.25 \\
Primary tumor type & $25(24.0)$ & \\
$\quad$ Breast cancer & $5(17.2)$ & \\
NSCLC & $6(30.0)$ & \\
SCLC & $7(17.1)$ & \\
CUP & & \\
Other tumor types & $41(23.6)$ & 0.80 \\
Number of cerebral lesions & $19(25.3)$ & \\
1 & & \\
2 or 3 & $22(21.2)$ & 0.42 \\
Extra-cerebral metastasis & $38(26.2)$ & \\
$\quad$ Yes & & \\
No & $33(25.8)$ & \\
Time from tumor diagnosis & $27(22.3)$ & \\
to treatment of cerebral metastasis & \\
$\leq 9$ Months & \\
$\geq 10$ Months & & \\
\hline
\end{tabular}

NSCLC: Non-small cell lung cancer; SCLC: small-cell lung cancer; CUP: cancer of unknown primary.

33 patients $(13.3 \%)$, and seizures plus other symptoms were recorded for additional 27 patients $(10.8 \%)$. None of the investigated characteristics showed a significant association with the occurrence of pre-treatment seizures (Table II).

The univariate analyses of survival revealed significantly better outcomes for age $\leq 60$ years, $(p<0.001)$, a Karnofsky performance score of $\geq 80 \%$ ( $p=0.001)$, more favorable primary tumor type (breast cancer or lung cancer, $p=0.003$ ) and no extracerebral metastasis $(p<0.001)$ (Table III). For pre-treatment symptoms $(p=0.46)$ and pre-treatment seizures $(p=0.30)$, no significant correlation with survival was found, although patients with seizures appeared to have a better prognosis. Age ( $p=0.008)$, Karnofsky performance score $(p=0.004)$, primary tumor type $(p<0.001)$ and extra-cerebral metastasis $(p<0.001)$ were also significant in the multivariate analysis and, therefore, considered independent prognostic characteristics (Table IV).

\section{Discussion}

Patients with a very limited number of cerebral metastases generally have more favorable survival prognoses than patients with many lesions (2). A considerable proportion of 
Table III. Results of the univariate analyses of survival.

\begin{tabular}{|c|c|c|c|c|c|c|}
\hline Characteristic & & $\begin{array}{c}\text { At } 6 \text { months } \\
(\%)\end{array}$ & $\begin{array}{l}\text { At } 12 \text { months } \\
(\%)\end{array}$ & $\begin{array}{l}\text { At } 18 \text { months } \\
(\%)\end{array}$ & $\begin{array}{l}\text { At } 24 \text { months } \\
(\%)\end{array}$ & $p$-Value \\
\hline \multirow[t]{4}{*}{ Pre-treatment symptoms } & No symptoms & 60 & 30 & n.a. & n.a. & 0.46 \\
\hline & Seizures alone & 73 & 66 & 44 & 30 & \\
\hline & Seizures+others & 74 & 52 & 36 & 18 & \\
\hline & Other symptoms alone & 66 & 46 & 33 & 25 & \\
\hline \multirow[t]{2}{*}{ Pre-treatment seizures } & Seizures & 73 & 60 & 40 & 25 & 0.30 \\
\hline & No seizures & 66 & 46 & 33 & 24 & \\
\hline \multirow[t]{2}{*}{ Age } & $\leq 60$ Years & 79 & 61 & 43 & 32 & $<0.001$ \\
\hline & $\geq 61$ Years & 57 & 38 & 27 & 14 & \\
\hline \multirow[t]{2}{*}{ Gender } & Female & 72 & 54 & 38 & 25 & 0.20 \\
\hline & Male & 63 & 44 & 31 & 24 & \\
\hline \multirow{2}{*}{ Karnofsky performance score } & $\leq 70 \%$ & 56 & 34 & 24 & 24 & 0.001 \\
\hline & $\geq 80 \%$ & 74 & 58 & 41 & 25 & \\
\hline \multirow[t]{5}{*}{ Primary tumor type } & Breast cancer & 76 & 64 & 46 & 36 & 0.003 \\
\hline & NSCLC & 70 & 50 & 35 & 26 & \\
\hline & SCLC & 72 & 55 & 30 & 22 & \\
\hline & CUP & 45 & 17 & 17 & 0 & \\
\hline & Other tumor types & 56 & 36 & 29 & 19 & \\
\hline \multirow[t]{2}{*}{ Number of cerebral lesions } & 1 & 71 & 51 & 37 & 25 & 0.22 \\
\hline & 2 or 3 & 60 & 46 & 29 & 21 & \\
\hline \multirow[t]{2}{*}{ Extra-cerebral metastasis } & Yes & 55 & 34 & 23 & 19 & $<0.001$ \\
\hline & No & 77 & 61 & 43 & 27 & \\
\hline \multirow{2}{*}{$\begin{array}{l}\text { Time from tumor diagnosis } \\
\text { to treatment of cerebral metastasis }\end{array}$} & $\leq 9$ Months & 67 & 45 & 32 & 18 & \\
\hline & $\geq 10$ Months & 68 & 53 & 38 & 30 & 0.19 \\
\hline
\end{tabular}

NSCLC: Non-small cell lung cancer; SCLC: small-cell lung cancer; CUP: cancer of unknown primary; n.a.: not available; bold values represent significant $p$-values.

patients with 1-3 lesions receive local treatment with or without WBRT. In randomized trials, the addition of WBRT led to an improvement in 1-year intracerebral control but was associated with greater neuro-cognitive decline 3 to 4 months following treatment $(10,11)$. However, an intracerebral recurrence can also be associated with neuro-cognitive deficits. Thus, careful patient selection is required when assigning a treatment regimen with or without WBRT in addition to neurosurgery or SRS to patients with 1-3 cerebral metastases. Scoring systems were developed to predict the risk of an individual patient to develop new cerebral metastases following SRS alone (5-7). In a study of 214 patients treated with SRS alone for 1-3 cerebral metastases, three groups were defined based on the number of lesions, extra-cerebral metastasis and primary tumor type (6). The risk of developing new distant cerebral metastases within 6 months after SRS was $64 \%, 35 \%$ and $20 \%$, respectively, and the risk after 12 months was $73 \%, 56 \%$ and $29 \%$, respectively. Patients of the first group and selected patients of the second group appeared more likely to benefit from WBRT when added to SRS. Therefore, a local therapy like SRS supplemented by WBRT is still a good option for many patients with 1-3 cerebral lesions (2, 5-7).

Patients assigned to this treatment regimen are at risk of experiencing seizures, mostly prior to the start of treatment
Table IV. Results of the multivariate analysis of survival.

\begin{tabular}{lccr}
\hline Factor & $\begin{array}{c}\text { Risk } \\
\text { ratio }\end{array}$ & $\begin{array}{c}95 \% \text {-Confidence } \\
\text { interval }\end{array}$ & $p$-Value \\
\hline Age & 1.61 & $1.14-2.28$ & $\mathbf{0 . 0 0 8}$ \\
Karnofsky performance score & 1.62 & $1.17-2.23$ & $\mathbf{0 . 0 0 4}$ \\
Primary tumor type & 1.06 & $1.00-1.12$ & $\mathbf{0 . 0 4 0}$ \\
Extra-cerebral metastasis & 1.83 & $1.34-2.51$ & $\mathbf{< 0 . 0 0 1}$ \\
\hline
\end{tabular}

Bold values represent significant $p$-values.

(12). The probability of pre-treatment seizures depends on the type of treatment and the number of lesions $(8,9)$. In a previous study, the number of lesions was inversely correlated with the rate of seizures in non-operated patients, whereas no significant correlation was found for pretreatment seizures in operated patients (8). In that study, seizures occurred in $33.3 \%$ of non-operated patients with a single lesion compared to $16.5 \%$ of patients with more than one lesion $(p=0.007)$. Thus, patients with a single lesion who are treated with a non-surgical local therapy plus WBRT appeared to have a comparably high risk of seizures. This applied to 45 patients of the present study. In another previous study that included only patients receiving a 
resection of their brain metastases, pre-operative seizures were observed significantly more often in patients with more than two lesions $(p=0.013)$ (9). A comparison of the previous and our present study regarding this finding is not reasonable, since in our study only two patients $(1 \%)$ of those 163 patients receiving neurosurgical resection had more than two lesions.

In the present study, the prevalence of seizures was $24.1 \%$, which was within the range of $12-35 \%$ reported for patients with cerebral metastases $(8,12-14)$. Another issue investigated in the current study was the identification of risk factors for the occurrence of seizures, but no significant risk factors were identified. This can be explained by the fact that the study was limited to patients with 1-3 cerebral lesions. Therefore, the number of lesions, one of the most important risk factors previously identified, could not play a significant role as in other studies $(8,9)$. Moreover, the prognostic role of the number of lesions depends on the type of treatment. In non-operated patients, single brain metastasis was reported to be significantly associated with seizures (8), whereas in operated patients, occurrence of pre-treatment seizures was associated with more than two lesions (9). Since the present study included both patients receiving and not receiving neurosurgical resection, a significant association between seizures and the number of lesions might not have been expected.

Another previously identified risk factor for occurrence of seizures is the primary tumor type $(1,12)$. Due to the fact that the patients of this study represented a very specific group, the distribution of primary tumors was different to other series, particularly regarding the proportion of melanoma patients $(2,15-20)$. This likely had an impact on the difference regarding the prognostic role of the primary tumor type between the current and previous studies. However, this difference also shows that it is reasonable to separately analyze the different treatment groups of patients with cerebral metastases.

In this study, pre-treatment seizures were not significantly associated with survival, although patients with seizures alone had the best outcomes of all groups categorized according to their pre-treatment symptoms. Moreover, patients with seizures had a non-significantly better survival than patients without seizures. A positive correlation between seizures and survival has been previously reported for patients with primary brain tumors $(1,21)$. In contrast to pretreatment seizures, we found significant associations between improved survival and age $\leq 60$ years, Karnofsky performance score $\geq 80 \%$, favorable primary tumor types and lack of extra-cerebral metastasis. These characteristics have been previously recognized as significant predictors of survival in patients irradiated for cerebral metastasis, consistent with the findings of the present study (15-20). However, when interpreting these findings, the retrospective design of this study should be taken into account because its nature bears the risk of a hidden selection bias.

In summary, the prevalence of pre-treatment seizures in this cohort of patients treated with a local therapy plus WBRT for 1-3 cerebral metastases was comparably high. Significant risk factors for the occurrence of pre-treatment seizures were not identified. Significant associations between seizures and survival were also not identified. Additional clinical research (ideally prospective studies) is warranted to better understand the role of seizures in this specific group of patients.

\section{Conflicts of Interest}

The Authors state that there is no conflict of interest related to this study.

\section{Authors' Contributions}

All Authors participated in the design of the study. J.W. and D.R. provided data, which were analyzed by S.E.S. and D.R. The interpretation of the data was done by all Authors. J.W., S.E.S. and D.R. drafted the manuscript, which was reviewed and approved in its final form by all Authors.

\section{Acknowledgements}

As part of the NorDigHealth project, the study was funded by the European Regional Development Fund through the Interreg Deutschland-Danmark program (087-1.1-18).

\section{References}

1 Englot DJ, Chang EF and Vecht CJ: Epilepsy and brain tumors. Handb Clin Neurol 134: 267-285, 2016. PMID: 26948360. DOI: 10.1016/B978-0-12-802997-8.00016-5

2 Tsao MN, Rades D, Wirth A, Lo SS, Danielson BL, Gaspar LE, Sperduto PW, Vogelbaum MA, Radawski JD, Wang JZ, Gillin MT, Mohideen N, Hahn CA and Chang EL: Radiotherapeutic and surgical management for newly diagnosed brain metastasis(es): An American Society for Radiation Oncology evidence-based guideline. Pract Radiat Oncol 2: 210-225, 2012. PMID: 25925626. DOI: 10.1016/j.prro.2011.12.004

3 Rades D, Hansen HC, Dziggel L, Janssen S and Schild SE: Prognostic role of pre-treatment symptoms for survival of patients irradiated for brain metastases. Anticancer Res 39: 4273-4277, 2019. PMID: 31366517. DOI: 10.21873/anticanres. 13591

4 Khan M, Lin J, Liao G, Li R, Wang B, Xie G, Zheng J and Yuan Y: Comparison of WBRT alone, SRS alone, and their combination in the treatment of one or more brain metastases: Review and meta-analysis. Tumour Biol 39: 1010428317702903, 2017. PMID: 28675121. DOI: 10.1177/1010428317702903

5 Rades D, Dziggel L, Blanck O, Gebauer N, Bartscht T and Schild SE: Predicting the risk of developing new cerebral lesions after stereotactic radiosurgery or fractionated stereotactic radiotherapy for brain metastases from renal cell carcinoma. 
Anticancer Res 38: 2973-2976, 2018. PMID: 29715126. DOI: 10.21873/anticanres. 12548

6 Huttenlocher S, Dziggel L, Hornung D, Blanck O, Schild SE and Rades D: A new prognostic instrument to predict the probability of developing new cerebral metastases after radiosurgery alone. Radiat Oncol 9: 215, 2014. PMID: 25240823. DOI: 10.1186/ 1748-717X-9-215

7 Huttenlocher S, Sehmisch L, Schild SE, Blank O, Hornung D and Rades D: Identifying melanoma patients with 1-3 brain metastases who may benefit from whole-brain irradiation in addition to radiosurgery. Anticancer Res 34: 5589-5592, 2014. PMID: 25275060.

8 Wolpert F, Lareida A, Terziev R, Grossenbacher B, Neidert MC, Roth P, Poryazova R, Imbach L, Le Rhun E and Weller M. Risk factors for the development of epilepsy in patients with brain metastasis. Neuro Oncol pii: noz172, 2019. PMID: 31498867. DOI: 10.1093/neuonc/noz172

9 Wu A, Weingart JD, Gallia GL, Lim M, Brem H, Bettegowda C and Chaichana KL: Risk factors for preoperative seizures and loss of seizure control in patients undergoing surgery for metastatic brain tumors. World Neurosurg 104: 120-128, 2017. PMID: 28512046. DOI: 10.1016/j.wneu.2017.05.028

10 Chang EL, Wefel JS, Hess KR, Allen PK, Lang FF, Kornguth DG, Arbuckle RB, Swint JM, Shiu AS, Maor MH and Meyers CA: Neurocognition in patients with brain metastases treated with radiosurgery or radiosurgery plus whole-brain irradiation: a randomised controlled trial. Lancet Oncol 10: 1037-1044, 2009. PMID: 19801201. DOI: 10.1016/S1470-2045(09)70263-3

11 Brown PD, Jaeckle K, Ballman KV, Farace E, Cerhan JH, Anderson SK, Carrero XW, Barker FG 2nd, Deming R, Burri SH, Ménard C, Chung C, Stieber VW, Pollock BE, Galanis E, Buckner JC and Asher AL: Effect of radiosurgery alone vs radiosurgery with whole brain radiation therapy on cognitive function in patients with 1 to 3 brain metastases: A randomized clinical trial. JAMA 316: 401-409, 2016. PMID: 27458945. DOI: $10.1001 /$ jama.2016.9839

12 Rudà R, Mo F and Pellerino A: Epilepsy in brain metastasis: an emerging entity. Curr Treat Options Neurol 22: 6, 2020. PMID: 32034533. DOI: 10.1007/s11940-020-0613-y

13 Rostami R, Mittal S, Rostami P, Tavassoli F and Jabbari B: Brain metastasis in breast cancer: A comprehensive literature review. J Neurooncol 127: 407-414, 2016. PMID: 26909695. DOI: $10.1007 / \mathrm{s} 11060-016-2075-3$
14 Chan V, Sahgal A, Egeto P, Schweizer T and Das S: Incidence of seizure in adult patients with intracranial metastatic disease. J Neurooncol 131: 619-624, 2017. PMID: 27878505. DOI: 10.1007/s11060-016-2335-2

15 Sperduto PW, Berkey B, Gaspar LE, Mehta M and Curran W: A new prognostic index and comparison to three other indices for patients with brain metastases: an analysis of 1,960 patients in the RTOG database. Int J Radiat Oncol Biol Phys 70: 510-514, 2008. PMID: 17931798. DOI: 10.1016/j.jirobp.2007.06.074

16 Gaspar L, Scott C, Rotman M, Asbell S, Phillips T, Wasserman T, McKenna WG and Byhardt R: Recursive partitioning analysis (RPA) of prognostic factors in three Radiation Therapy Oncology Group (RTOG) brain metastases trials. Int J Radiat Oncol Biol Phys 37: 745-751, 1997. PMID: 9128946. DOI: 10.1016/s0360-3016(96)00619-0

17 Rades D, Dunst J and Schild SE: A new scoring system to predicting the survival of patients treated with whole-brain radiotherapy for brain metastases. Strahlenther Onkol 184: 251255, 2008. PMID: 18427755. DOI: 10.1007/s00066-008-1831-5

18 Rades D, Dziggel L, Nagy V, Segedin B, Lohynska R, Veninga T, Khoa MT, Trang NT and Schild SE: A new survival score for patients with brain metastases who received whole-brain radiotherapy (WBRT) alone. Radiother Oncol 108: 123-127, 2013. PMID: 23830191. DOI: 10.1016/j.radonc.2013.06.009

19 Rades D, Huttenlocher S, Dziggel L, Blanck O, Hornung D, Mai KT, Ngo TT, Van Pham T and Schild S: A new tool to predict survival after radiosurgery alone for newly diagnosed cerebral metastases. Asian Pac J Cancer Prev 16: 2967-2970, 2015. PMID: 25854390. DOI: 10.7314/apjcp.2015.16.7.2967

20 Rades D, Blanck O, Khoa MT, Van Thai P, Hung NQ, Dziggel L and Schild SE: Validation of a survival score for patients receiving radiosurgery or fractionated stereotactic radiotherapy for 1 to 3 brain metastases. In Vivo 32: 381-384, 2018. PMID: 29475924. DOI: 10.21873/invivo.11249

21 Lote K, Stenwig AE, Skullerud K and Hirschberg H: Prevalence and prognostic significance of epilepsy in patients with gliomas. Eur J Cancer 34: 98-102, 1998. PMID: 9624245. DOI: 10.1016/s0959-8049(97)00374-2

Received April 17, 2020

Revised April 27, 2020

Accepted April 28, 2020 